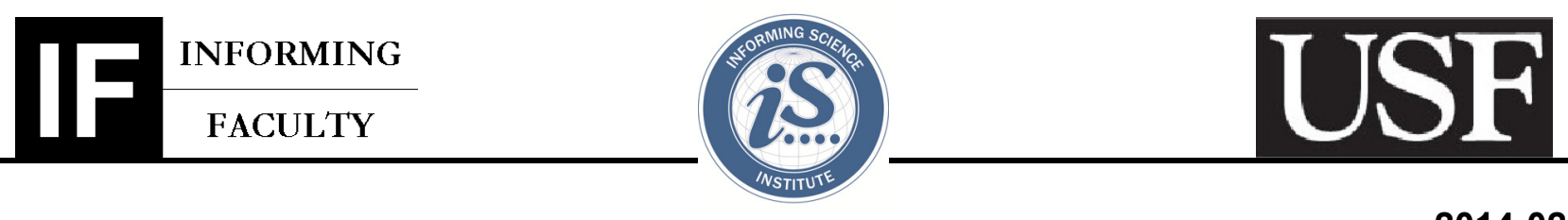

2014-02-5

GRANDON GILL, MATTT MULLARKEY

September 1, 2014

\title{
TAKING ISM4300 ONLINE
}

Since we turned this class into a case method class with an emphasis on student participation in business case discussions, it has worked really well in the classroom. But can we translate this success from the physical synchronous interaction to the online asynchronous virtual format?

Grandon Gill, Professor in the Information Systems and Decision Sciences (IS\&DS) department at the University of South Florida's College of Business, looked over the Canvas course site for ISM4300 that he was creating. The structure of the course was going to be radically different - complex business cases "discussed" in an online virtual environment - from anything his students had experienced in their Information Systems degree program. Before the course got too far along, he needed to be sure that students understood the course requirements and the operation of this online environment and felt personally invested in the class. But was having them discuss a case about the class itself a reasonable way to accomplish this? He sure hoped so...

ISM4300 was the capstone course for the department's undergraduate MIS major. Its main objective was to help students learn how to apply the knowledge they had gained over the course of their IS major. This learning was to be achieved in two ways:

1. Case Discussions: Each week students would discuss an in-depth case study of a particular IT-related decision. These cases profiled both business decisions made in IT-focused companies and IT-decisions made in any type of organization. All had been developed by IS\&DS faculty members and Ph.D. students at USF and most involved local businesses.

2. Individual Projects: A term project—which could either be technological or research-focusedchosen by the student intended to demonstrate key elements of what he or she had learned in the program presented to and evaluated by his or her peers and the instructor(s).

Both Gill and his co-Instructor, Matt Mullarkey, had taught the course previously with success. But it had never been delivered entirely online before. This required some key decisions. These included:

- How should discussion participation be weighted versus project reports and presentation?

- $\quad$ Should a detailed grading rubric be established for discussions?

- Should late work be accepted or penalized?

- How much flexibility should be offered in project layouts and online delivery?

- Should the online activities be entirely asynchronous or should synchronous sessions be offered?

This case was prepared for the purpose of class discussion, and not to illustrate the effective or ineffective handling of an administrative or classroom situation and is copyrighted by the Informing Science Institute. Permission to make digital or paper copy of part or all of these works for personal or classroom use is granted without fee provided that the copies are not made or distributed for profit or commercial advantage AND that copies 1) bear this notice in full and 2) give the full citation on the first page. It is permissible to abstract these works so long as credit is given. To copy in all other cases or to republish or to post on a server or to redistribute to lists requires specific permission and payment of a fee. Contact Publisher@InformingScience.org to request redistribution permission.
Gill did not feel strongly about the specific outcome of any of these decisions, but he suspected that his students might feel otherwise. He hoped that discussing the case and these issues would help him better determine what should be done. In fact, he planned to leave the decisions to the class as a whole- provided that they could come to a consensus. 


\section{Background}

The course being taught by Gill was the capstone course for the undergraduate MIS major. It had now been offered in a case method/project format for over two years. Important factors that have influenced this design were (1) the nature of the MIS major itself, (2) the role of the capstone course in integrating and evaluating student learning outcomes, and (3) a grant from the National Science Foundation to develop and test a new approach to the course.

\section{Undergraduate MIS Program at USF}

The undergraduate MIS program at USF was offered by the IS\&DS Department of USF's College of Business. Typically, between 200 and 300 students pursued the major at a given time, although the number had been as high as 1100 during the internet bubble period of 1999-2001.

Because students received a business degree rather than a computer science or engineering degree at the end of the program, the number of MIS-specific courses required was relatively small: 8 courses out of a total of 20 courses - mainly in other areas of business - that students took in their junior and senior years as undergraduates. For this reason, many of the courses offered in the program-shown in Exhibit 1-represented surveys of important IT topics (e.g., programming, analysis and design, data communications) with relatively limited opportunities to apply what was learned in subsequent courses. The one exception to this was the database topic, part of the department's emphasis on business intelligence, where several higher level courses building on early skills were offered.

Because of the limited number of credit hours available, great care had to be taken in designing each of the courses that each student was required to take. Four of these courses covered relatively distinct topics: programming (ISM3232), systems analysis and design (ISM3113), databases (ISM4212), and data communications (ISM4220). The final course in the major, ISM4300, was an exception, however. It was supposed to help students synthesize and apply what they had learned in earlier courses - on both the technical and business sides. A course of this type was normally referred to as a capstone course.

\section{Role of a Capstone Course}

Any educational program faces two important challenges: assessing what students have learned and ensuring that they are able to use that learning outside of the classroom. A particularly important way of addressing this challenge involves offering a course known as a capstone. The purpose of a capstone course is to provide students with the opportunity to apply what they have learned over the course of the program in a context where "what to do next" is not obvious or dictated by a textbook. How well students perform in such a course also provides important evidence of what they have managed to retain from earlier courses in their program.

Designing an effective capstone course for a program such as the USF MIS major was a difficult problem because of the variety of student skills and interests coming in. On the one hand, the course could be taught entirely from a business perspective. While certainly valuable, such a course would do little to reinforce the technical content students had learned in the IS discipline. On the other hand, some schools made their capstone a pure project course. At USF, however, focusing entirely on the technical side would be problematic.

Some students, particularly those interested in technology, might have taken three courses in technical areas such as programming or databases, while others might have stopped after the required introductory course. Finding a project that would be challenging for-but not beyond the skills of - all students would be nearly impossible.

One possible approach to the capstone design was suggested by Gill's experiences teaching the capstone course of the department's master's degree program. That design, the winner of an international competition for "innovative instruction" from the Decision Sciences Institute in 2005, was built around a mixture of case discussions and research projects. There were two obstacles to applying that model directly, however: 
1. The cases used in the MS-MIS capstone were almost all developed by Harvard Business School - Gill's alma mater - and were designed for MBA students. As such, they tended to involve decisions that would likely seem far removed from those USF undergraduates would be facing in the first decade of their career.

2. The research component of the MS-MIS course represented an area that was not emphasized in the undergraduate curriculum. While Gill felt that undergraduate students could do a reasonable job on the activities, they would not particularly reinforce the skills acquired earlier in the major.

With respect to the second of these issues, Gill felt that a flexible project option — one that gave students the ability to choose the type of project that they would pursue - could replace the research elements.

With respect to the relevance of the discussion cases, however, new materials would need to be developed.

\section{NSF Grant}

The desire to develop a set of case studies that could be used as the core of the undergraduate capstone course motivated Gill to propose a project to the National Science Foundation (NSF), which had a number of programs designed to further STEM (science, technology, engineering, and mathematics) education. The objectives of the project were ambitious. As described in the proposal abstract:

The University of South Florida is exploring the use of authentic, open cases in STEM subjects in a capstone course for an undergraduate MIS program. In addition to developing and teaching the course itself, the project entails: 1) the creation of roughly 12 new case studies involving technological decision situations written at a level appropriate for undergraduates, 2) a faculty workshop on case method facilitation and case writing, 3) publication of a book specifically designed to support the workshop, available both in print form and electronically downloadable at no cost through a Creative Commons license, and 4) publication of the cases produced under the grant in a peer-reviewed outlet that offers free access to STEM educators.

Within the abstract, the term "authentic" referred to the fact that the cases to be developed were going to be based on real organizations and people, rather than being fictional. The term "open" meant that the cases were not expected to have a right answer; instead there would be many good (and a far greater number of bad) solutions and students would be expected to exercise their judgment to distinguish between them.

One key aspect of the proposal was that many different MIS and other faculty members would become involved in writing the cases and - eventually - teaching the capstone course. Although discussion case writing was a staple of the research at HBS, it was a foreign activity to most faculty researchers, whose training was oriented towards producing journal articles. Gill hoped to see that changed as the project progressed. Moreover, his goal was that the process should produce a collection of cases that would be available for use by MIS programs throughout the world at no cost. He further intended that the materials he developed for faculty members on case writing and case facilitation would be similarly available.

In targeting case sites appropriate for undergraduates, Gill envisioned emphasizing local companies - those likely to be future employers of USF graduates - and small businesses, whose issues were likely to seem most relevant to undergraduates. Of particular interest were organizations whose decision-makers could be convinced to sit in on class discussions and then offer their experienced viewpoint once the discussion was completed.

Another aspect of the grant was built around trying to assess the learning that took place as a result of the discussions over the course of the semester. This had long been an obstacle to discussion-based learning. Unlike lectures that emphasized testable content, case discussions often left students with the perception that they had learned a great deal from the process, but unable to identify what it was that they had learned. This was a problem everywhere that cases were used, including HBS. Gill had proposed using a variety of different approaches to measuring learning. 
In April 2011, the proposal that Gill had submitted was approved by NSF, scheduled to begin on 1 June 2011. In early May 2011, Gill held a week-long workshop for members of the proposal team (including IS\&DS department chair, Dr. Kaushal Chari, and Dr. Manish Agrawal, both of whom were Co-Principal Investigators on the grant) and other interested faculty members. Over the course of the summer and fall of that year, Gill and several faculty participants on the project team began developing case studies as part of the two year project. It was not until January 2012, just a few days before the first offering of the newly designed course was scheduled to begin, that he completed the syllabus for the face-to-face version of the class.

Since that its original offering, the number of cases developed for the class had more than doubled. In fact, every semester the course was taught at least two new cases had been added to the course, with cases previously used being retired. The new cases added a particularly engaging element to the class since, in most instances, the decision-makers involved in the case actually sat in on the class discussion and then commented upon it.

\section{The Case Method}

The core of the redesigned ISM4300 was the use of the case discussions according to a protocol that is commonly known as the "case method". This particular approach was first introduced early in the $20^{\text {th }}$ century at Harvard Business School (HBS). Whereas traditional lecture-based teaching is normally focused on conveying content (e.g., facts, theories and problem-solving methods), the case method is particularly focused on building the participant's capacity to make sound judgments through integrating many diverse sources of information.

\section{Discussion Case Studies}

The case method is built around a discussion case study. Unlike the "case studies" that appear frequently in textbooks to present a real world example, or the business cases that appear on corporate web sites to illustrate the successful use of a product, discussion cases provide a detailed description of a real-world business, organizational, or personal situation for which one or more decisions must be made. It is in the analysis of these decisions that judgment is required.

The decision-oriented focus of the case is critical. Whereas case studies developed for research or illustrative purposes provide stories that describe the outcome of a particular situation, the discussion case stops at the point where the decision must be made. The participants in the case discussion then examine the situation from the perspective of central figures on the case - referred to as the case protagonists - and attempt to come up with sensible decisions. In most of these situations, there is no right or wrong decision. Rather, there are some decisions that make sense, and many more that probably do not. The goal of analyzing the case study is to come up with at least one sensible course of action and to eliminate as many bad choices as possible.

Discussion case studies tend to be relatively long, since few situations encountered in organizations can adequately be described in a paragraph or two. Normally, discussion case studies are divided into two sections: the body of the case and exhibits containing tables, illustrations, and reference materials. The length serves two purposes. First, it allows the situation to be described in whatever detail is necessary-although even the longest case study will require the reader to make some assumptions since it is impossible to cover everything. By the same token, the length of the case means that some of the details mentioned in the case will not be particularly relevant to the decision. This is valuable because being able to distinguish between important and unimportant facts is necessary in any non-trivial decision. In organizations, an unambiguous roadmap that identifies what you really should know is almost never available.

\section{In-Class Case Discussions}

A typical case discussion, as conducted at schools such as HBS, takes place in four stages: 1) student preparation, 2) the opening, 3) the discussion, and 4) the summation. 


\section{Preparation}

Before a useful case discussion can take place, students must be prepared. Preparing a case study is a timeconsuming process; even experienced MBA students typically require about two hours if they are going to be adequately prepared. While it varies across individuals, case preparation normally involves:

- Reading the case to get the "big picture"

- Going through the case in detail, taking notes on the body and the case exhibits

- Preparing an outline of key points likely to be encountered during the discussion

Some faculty members choose to assign pre-case study questions while others prefer to let students determine relevant questions on their own. The advantage of pre-case questions is that they tend to focus the student's preparation on the most important issues of the case. That is also the disadvantage of such questions, however. In real world settings, as noted earlier, what is important and unimportant is often hard to distinguish.

In case method programs students often get together to compare notes and ideas during their preparation. Unlike some types of homework - where such collaboration is prohibited and treated as a form of "cheating"- virtually all faculty members who lead discussion classes actively encourage students to get together while preparing their cases prior to class.

\section{The Opening}

In order to start a case discussion, the faculty member - usually referred to as the facilitator-will typically call upon a student to open. There are a number of variations in this process. The first involves asking for a volunteer to open versus the "cold call". In the case of the latter, the facilitator chooses a student to open without any advance notice. It is, by far, the more common approach in programs that rely heavily on the case method.

The cold call offers several advantages over using volunteers to open, and one key disadvantage. The advantages are that it provides a strong motivation for students to come into the class well-prepared. Trying to open when unprepared is something few students would care to repeat. Along the same lines, it provides an alternative to forcing students to prepare by making them write a summary of each case prior to class - a requirement annoying to students and instructors alike. Finally, as the semester progresses, it provides the facilitator with the opportunity to encourage participation from students who have been reluctant to contribute to discussions in the early classes. On the disadvantage side, some students view this as a mixed blessing and, more importantly, an unprepared opening does little to benefit the class.

The manner in which the facilitator asks a student to open also varies. Some facilitators ask the opener a very specific question. Others choose a more general question, such as "What do you think [the protagonist's name] should do?" or simply ask "Would you care to open?" While the opening progresses, the facilitator will often write an outline of what is being said on the board. The mark of a good opening is that the outline on the board makes sense and seems to be well organized.

The most effectively openings for a typical discussion case tend to proceed along the following lines:

I. The issue being faced is briefly described

II. The recommended decision or decisions are summarized

III. Key elements of background are presented

IV. The rationale for the recommendations is presented

Students often find themselves starting with Item III, making the opening more like a detective story as the facilitator and class wait for Item II - not presented until the very end (if at all). The suspense value generated by this approach rarely justifies the confusion caused by the flood of seemingly-irrelevant details that occurs in presenting the background first. In addition, the best openings proceed on the assumption that the 
rest of the class and the facilitator are aware of the case facts; the purpose of the opening should therefore be to separate the important from the unimportant. Good openings do not simply rehash the case itself.

\section{The Discussion}

The heart of the case method is the discussion of the case. The assumption here is that even thorough preparation of a case does not guarantee that a student will understand all the nuances of a particular situation. By discussing the case with others - under the direction of an experienced facilitator - many of these nuances come to the surface. Often, what is said leads participants to rethink their initial recommendations. This is viewed as a good thing. If the process of discussing a case led to no changes in opinion, there would be no point in having such discussions.

The facilitator's role in the case discussion is very different from that of the faculty lecturer. When a class is well-prepared, the vast majority of the facilitator's comments will be in the form of questions to participants. From time to time, the facilitator may point out a case fact or add background information. On the whole, however, the best discussion leader is the one that elicits most or all information from the participants themselves.

Aside from asking questions, the facilitator will sometimes play the devil's advocate - making a case for an alternative viewpoint or solution when the class appears to be reaching a consensus. A facilitator will also sometimes attempt to lead the class towards a solution then, as consensus starts to form, will raise questions that highlight its weaknesses. Participants quickly come to recognize that such techniques are used to serve the needs of the discussion process; they do not necessarily (or even usually) represent the facilitator's personal views.

In a case method course, discussion participation typically accounts for a large proportion of the student's overall grade (at HBS, more than $50 \%$ is the usual, with exams counting for the rest). Judging participation, however, is highly subjective. That being said, there are certain types of contributions that are nearly always welcome and are likely to add to a student's overall assessment. These include:

- Comments linking a situation in one case to another case that was previously discussed

- Comments that bring in ideas from other classes

- Comments that link a participant's own personal experiences to the case

- Comments that offer a well-thought-out competing point of view to a discussion where the class seems to be in agreement

- Comments that offer an integrative perspective that goes beyond the specific focus of the case (e.g., relating to ethics, involving business functions beyond the specific area of a course, such as MIS).

Similarly, there are some comments that are unlikely to add much to a student's participation tally. These include:

- Simple statements of agreement that do not offer new evidence

- Arbitrary changes of topic during the course of an active discussion that has not started to wind down

- Comments that relate to an earlier topic from which the discussion has already moved on

- Comments that appear genuinely disrespectful of the opinions of individual participants

With respect to the last of these, some common sense must be applied. Some facilitators use an exaggerated style that involves intentionally making provocative remarks; some students mimic that style as well. Such parody should not be confused with genuine disrespect.

\section{The Summary}

At the end of each discussion, a facilitator will generally spend 10-15 minutes reflecting on the discussion. Sometimes, the actual decision or set of decisions made by the organization or individual featured in the case 
will also be specified. The goal of such reflection is generally not to identify the "right" decision or to imply that whatever decisions were made were the correct ones. Rather, it is to help students better understand the types of situations to which the lessons of the case might apply.

In early cases, the facilitator may also use the summary to introduce frameworks that might apply to later cases. Generally such frameworks are offered as something that might be useful, rather than as theory that must be applied in later cases. As a general rule, adherents of the case method tend to be theory-agnostic. They have no objection to theory being applied where it is useful, but are reluctant to propose any theory or framework as being relevant to all situations.

\section{Online Case Discussions}

Online courses offer a number of potential advantages. In particular, an online capstone course might offer participants digital proximity, freeing them from geographic co-location requirements and strictures on the confines of a physical classroom, and a certain level of time independence on their participation in the course. For many USF IS students taking their final course of the undergraduate degree, these advantages could translate into freedom to schedule participation around full or part-time work, other classes, and collegiate extra-curricular activities.

Additionally, research shows that online environments may afford a higher quality interaction among students when it provides an opportunity for reflection on their own and their classmates' contributions prior to posting. These "threaded discussions" may compare favorably to a real-time in class interaction that requires students to speak and interact from a "top of mind" perspective [Meyer, K. A. (2007). Student perceptions of face-to-face and online discussions: The advantage goes to... Journal of Asynchronous Learning Networks, 11(4), 53-69]. In fact, in prior capstone classes Professors Gill and Mullarkey had both experienced the "quieter" student with important input to offer expressing a frustration over their inability or discomfort in making their voice heard.

Online "threaded" case discussions differed from the in-class case discussion in a number of ways. First and foremost, there were two fundamentally different approaches that could be used in delivering cases online:

1. Synchronous: The discussion takes place in real time, usually involving the use of a conferencing application such as Elluminate Live! (re-branded as Blackboard Collaborate), WebEx, or even in virtual worlds, such as Second Life.

2. Asynchronous: The discussion takes place on a text-based discussion board. Nearly all learning management systems, such as Canvas and Blackboard, supported this feature.

These two approaches placed different demands on the instructor and student and each had its pros and cons.

\section{Synchronous Discussions}

Synchronous case discussions tended to proceed in a manner very similar to classroom discussions. Most conferencing environments provided a shared whiteboard, so Gill could write on it (using a Tablet PC) in much the same way he would write on the board in the classroom (see Exhibit 2 for an example).

Gill's experiences had been that synchronous discussions on Elluminate/Blackboard Collaborate could be "nearly" as engaging as classroom discussions. This was particularly true when everybody involved had experience participating with one or two previous sessions. Past experience was particularly useful in reducing the frequency of technology problems. It tended to reduce the technology-related problems involved. Generally speaking, these problems fell into three categories:

1. Setup problems. Particularly when the computers or networks being used were provided by businesses or other institutions, firewalls and other forms of protection sometimes interfered with connections. Problems could also be encountered that were related to software installations, such as out of date versions of Java. These problems could often be resolved, or at least identified, with a test session prior to the actual online discussion. 
2. Microphone problems. Microphone problems seemed to come in two sub-classes. The first involved setup issues. Since the advent of multimedia, a typical PC often has several alternative microphone sources. Often, ensuring that the conferencing software was properly connected to the proper source was not a trivial matter. Furthermore, it was not unusual for certain background applications, such as speech-to-text software, to maintain a connection to a microphone that prevented other applications from using it. The other type of microphone problem involved feedback and echoes. The ideal microphone setup involved a headset or earpiece rather than the computer's speakers - which could feed back into the microphone producing an echo with half a second delay or more when an individual's microphone was not muted. Until participants experienced this first hand, however, they never seemed to believe how big a problem this could produce.

3. Internet connection problems. No matter how well prepared participants were, there was always the possibility that a connection would be dropped or find its bandwidth constricted. These types of problems seemed to be particularly prevalent during evening hours; Gill suspected that part of the reason might be the bandwidth consumed by streaming entertainment applications, such as Netflix, which tended to peak during evening time periods. It could also be the result of high usage of shared wireless connections, as sometimes occurred in apartment complexes, dormitories, or classrooms.

When synchronous discussions were working effectively, however, they also offered a couple of advantages over classroom discussions:

- They allowed remote participants to join the discussion. For example, the discussion pictured in Exhibit 2 included two participants - the authors of the case being discussed - connecting from Vietnam. The students taking that class - the only online session-had ended up giving that particular discussion the highest rating of the semester.

- Some individuals who felt uncomfortable speaking in the face-to-face classroom were much more willing to participate in the online environment. Thus, it could be more inclusive than the classroom environment.

Because of the prevalence of offshoring in IT, Gill felt that being able to function effectively online was a valuable skill for students. Thus, he had always conducted at least one online discussion each semester in his face-to-face classes. Interestingly, in the 10 years he had been doing this at the graduate level, 19 out of 20 of his sections had voluntary chosen to do a second synchronous session when given the choice.

It was also possible to conduct synchronous discussions in a virtual world, if the instructor was willing to forgo the whiteboard (Exhibit 3). Gill's experience had been that this could be even more engaging than the shared whiteboard of the conferencing applications; he was not sure why. The big drawback was that the technological issues seemed to multiply by a factor of ten when using this venue. Moreover, the problem did not seem to be getting any better with more powerful PCs and better bandwidth. As was true with gaming applications in general, the developers of such environments always designed virtual world applications to squeeze every ounce of performance out of high-end hardware. That invariably led to problems for any participant with an old or low-end system.

\section{Asynchronous Discussions}

Asynchronous threaded case discussions were markedly different from the normal face-to-face discussion because they were text-only and took place over an extended period of time (usually a week). Gill had used such discussions in graduate classes for 15 years. The approach that he used involved two stages: 
- Opening. For each case, a certain number of students (usually between 4 and 7, depending on class size) were designated "openers". Each was assigned a specific question and was instructed to create a new thread (top-level post) that addressed the question. Opening posts were to be made by a specific date and time; late openings were penalized because they interfered with the ability of the rest of the class to participate.

- Discussion: As soon as an opening thread was posted, the remainder of the class, as well as the original opener, could participate on the discussion thread. By the time openings were due, multiple threads were available for participation.

Exhibit 4 contains extracts from a discussion conducted in one of Gill's graduate capstone classes. The first image shows the seven top-level threads assigned to openers. The second image shows a short extract from one of the threads.

Asynchronous case discussions could become quite lengthy. Gill's past experiences suggested that having more than 25 participants in a single discussion could become unwieldy. For this reason, when a class reached a certain size - around 30 students - he would separate students into two distinct Canvas sections, each of which had its own separate discussion (invisible to the other section). Even so, discussions tended to become large. For example, the Exhibit 4 discussion took a week and involved 25 students. It had 137 posts (i.e., 5-6 posts per students) and, when printed out fully expanded, was nearly 40 pages.

Gill had recently worked with an instructional designer at USF who had expressed surprise- bordering on shock - at the size, depth, and quality of the typical discussion produced by his graduate class. Gill attributed this to two factors:

1. The strength and energy of the students

2. The assessment process.

While the first of these was not under his control, he had developed a variety of criteria that he used in grading each student's weekly participation. Specifically, when evaluating posts, he looked for the following:

- Flow of Discussion. With the exception of opening posts, each post should contribute to the discussion. He valued posts that referred to previous posts. Of particular value were contributions that (a) expressed well-reasoned disagreement with a previous poster, or (b) specifically added something new to a previous post.

- Novelty of Contribution. Gill completely discounted posts that merely agreed or repeated information from previous posts; too many of these could actually hurt a student since they only added volume, not value, to the discussion.

- Engagement. For many of his time-pressed students, the most efficient way to participate was to sit down for a few hours, compose a set of contributions, post them and then ignore the discussion for the rest of the week. For this reason, Gill looked at the date and time of all the posts made by each student and, if they clustered, he reduced the student's overall grade. This was aided by a feature provided by Canvas that made it easy to group each student's contributions.

- Use of case facts. Posts that referenced specific facts from the case were valued heavily compared with those that simply expressed unsupported opinions.

- Presentation. Numerous surveys of employers confirmed one single fact: the skill that was most prized was the ability to communicate effectively. Thus, Gill expected posts to be organized in a way that made them easy to read, grammatically sound, and devoid of excessing spelling errors. The only students for whom he relaxed these standards somewhat was the group that were nonnative English speakers.

Importantly, and in a manner completely consistent with the case discussion in-class presentation approach and prior online education research, when using this assessment approach the quality and quantity of the student performance was not dependent or even reliant on instructor participation in the threads [Arslanyilmaz 
\& Sullins. (2013). The extent of instructor participation in an online computer science course: How much is enough? Quarterly Review of Distance Education, 4(2), 63-74]. At the graduate level, once students understood how seriously Gill took these discussions, they responded to the challenge. He expected nothing less from his undergraduates.

\section{ISM4300 Design}

The ISM4300 course design consisted of two elements: the case discussions and the course project. The objective of the case discussions, as noted previously, was to give students practice in analyzing situations requiring judgment. The objective of the course project was to provide students with the opportunity to demonstrate and practice skills that they have acquired over the course of the MIS major.

\section{Required Case Discussions}

The online version of ISM4300 would draw upon the same set of locally developed cases as the face-to-face course. Because the class was specified as web-based, all required discussions would need to be conducted asynchronously, using the Canvas discussion tool. The in-class discussions of these cases were to be conducted largely according to the standard protocol described in the previous section. There were, however, two additional activities that Gill required:

1. A post-discussion reflection. Immediately after each discussion (combined with the break), student would fill out a form asking students:

i. What are the three most important things you learned from the case?

ii. How did the case discussion change your view of the case?

These would also be graded using 1 to 5 scale, with 3 being considered satisfactory performance.

2. A case evaluation form. A simple form used to gauge student reaction to each case study. An example of the form is included as Exhibit 5. These would not be graded, but students would get credit for making the submission.

These two activities would be wrapped into each student's participation grade. The purpose of the first was both to ensure that students came in prepared to discuss the case and to determine the pre-discussion range of perspectives of the case. The purpose of the second was to assess how the discussion had impacted student perceptions of the case.

\section{Required Course Project}

The second element of the capstone course was the course project. The objective of the project, described in detail in Exhibit 6, was to provide students with the opportunity to apply in-depth something that they learned over the course of the USF MIS major. The types of project allowed were intentionally broad and included programming projects, database projects, systems analysis and design projects, web site development, technology white papers, research projects, and even case studies.

Projects were to be individual efforts, rather than group efforts. About half-way through the semester, each student was expected to submit a project proposal. Gill would comment on these proposals and attempt to give students further direction, where needed.

The project cycle would end during the last two weeks of the semester. During this period, case discussions would be replaced by submission and evaluation of student science fair-style poster presentations. Each student would develop two deliverables that would describe his or her project:

1. A video presentation, lasting no more than 10 minutes, describing his or her project. This substituted for face-to-face presentations that students repeated roughly 10 times during the faceto-face version of the course.

2. A poster PDF that that describes the project. This substituted for tri-fold poster boards 
that students produced for the face-to-face version of the course.

In addition to submitting a project, each student would be assigned to peer review 7-10 projects and would be assessed on the quality of his or her reviews. Student assessments, as well as Gill and Mullarkey's own assessment, would be used in grading the projects.

\section{ISM4300 Grading and Design Issues}

Although the evaluation plan identified the elements of the course that would be evaluated, it did not specify how each measure would contribute to a student's grade. There were three key issues that needed to be addressed: overall weighting, use of a rubric, and deadlines.

\section{Overall Weighting}

The overall weighting decision involved determining how much weight should be given to in-class participation and how much should be given to project performance. While the weight of each component would be substantial, Gill was indifferent with respect to which was given greater weight. For simplicity's sake, he proposed 5 options:

1. $70 \%$ (participation) and $30 \%$ (project)

2. $60 \%$ (participation) and $40 \%$ (project)

3. $50 \%$ (participation) and $50 \%$ (project)

4. $40 \%$ (participation) and $60 \%$ (project)

5. $30 \%$ (participation) and $70 \%$ (project)

He was comfortable letting the class choose which of these weightings was to be employed.

\section{Use of a Rubric for Discussion Grading}

Even when overall weighting for the two course elements had been established, there remained the question of how to allocate points for the case discussions. With respect to the case discussions, for example, Gill had included general guidelines for effective participation (Exhibit 7). These could be translated into a strict rubric that could be used in grading each student's weekly participation and post- case reflections (Exhibit 8). Alternatively, he could use a more holistic grading approach. The advantage of the holistic approach was that if a student did particularly well in one particular dimension of participation, the other dimensions could be discounted. With a strict rubric, on the other hand, a few noticeable spelling errors could cause points to be lost on an otherwise outstanding post.

The obvious disadvantage to grading without a rubric was the intrinsic subjectivity of the process. For example, he and Mullarkey would both be grading some discussions - there was no guarantee that they would make the same assessment without using a rubric. But was this necessarily a bad thing?

Gill suspected that the overall average of the two approaches would be the same. That led Gill to propose a question: How would students prefer discussion grading be performed? Since Canvas made it easy to attach a rubric to an assignment, it would be the same work for him and Mullarkey in either case.

\section{Deadlines}

Some deadlines within the course were not negotiable: a given case had to be prepared by the student over the course of the week where it was discussed, opening posts needed to be made on time so as not to interfere with the discussion, projects needed to be complete before the peer evaluation period, and all work needed to be submitted before the end of the semester. There were, however, some areas of the course where deadlines —within limits—were somewhat arbitrary. These included:

- The project proposal deadline

- The due date for the reflections and evaluations that needed to be submitted after each discussion 
There were a number of different ways that these deadlines could be handled. First, they could be absolutewith no exceptions. Second, late submissions could be accepted with a penalty. Third, late assignments could be accepted with no penalty. While the last of these offered the greatest flexibility, it also presented the greatest risk to procrastinators, who could accumulate an unsustainable backlog of overdue assignments. Gill was happy to live with any of the three approaches, but would consistently apply whatever policy was chosen.

\section{Project Deliverables}

Another issue that concerned Gill was the manner in which projects were delivered. In the face-to-face environment, tri-fold poster boards with a particular layout and face-to-face presentations had been required more or less as a matter of necessity. Self-standing boards and personal presentations had been pretty much the only way the classroom could handle the number of projects involved.

In the online version of the class, the constraints were different. Multiple audio-visual formats could be accommodated. Similarly, posters could — in theory, at least — take many different forms. On the surface, having such flexibility would offer students fewer limitations on their creativity. In practice, however, such freedom would come with a price:

1. When it came time to peer review each other's projects, it would be much harder to make a consistent assessment when every project came in a different form. There would also be the danger that some projects would be delivered in forms that not everyone could read. For example, a Flash video would work on a PC or Mac, but not on an iPad or Android tablet.

2. When preparing projects, sometimes having a specific template rather than a blank page actually makes the process easier. Where complete freedom was the option chosen, for example, when students asked questions about how the project was to be delivered, the instructors would have little choice but to respond with the online equivalent of a shrug.

Within the Exhibit 6 descriptions of the project activity, the options specifying greater freedom of delivery are presented in italics. The more restrictive options would be Youtube or voice-over PowerPoint (for presentation) and use of the specified templates (for the poster).

\section{Synchronous Class Sessions}

Another potential decision that needed to be made was if any synchronous discussions would be held during the semester. Because the class was designated as a web-based class, and did not have an assigned time slot, Gill could not require students to attend such sessions. They could, however, be offered on an extra credit basis and scheduled on a rotating basis. Doing so would offer some advantages:

1. Generally speaking, the synchronous discussion was more fun for participants than the textbased discussion.

2. Synchronous sessions provided students with more immediate feedback from the instructor.

3. Synchronous sessions could allow some case protagonists to sit in on the discussions, as the decision-makers could do so from a remote location.

4. Discussions could also be recorded, so students who could not attend could watch the discussion at a later date.

To be fair, running regular synchronous discussions also had some disadvantages:

1. They would require additional time commitment from all involved. Discussion times usually ranged from 60-90 minutes. This would be on top of regular class participation in the asynchronous discussions, not a substitute for it. 
2. To be useful, students had to come to such discussions well prepared. No extra credit would be given to students who simply sat back and listened. If a discussion was a disaster with guests in attendance, "negative" extra credit might be awarded, since it would indicate a lack of professionalism on the part of those unprepared students involved.

3. There was a learning curve involved. Students would need to be technologically prepared to engage in the discussions, in addition to their case preparation. That could mean attending one or more practice sessions prior to participating in an actual discussion (particularly if a guest was involved).

Gill saw three potential options:

- Do not schedule any synchronous discussions

- Schedule synchronous discussions in rotating time periods and stop when attendance drops below a $20 \%$ threshold for two sessions

- Schedule synchronous sessions only when they will allow protagonists who want to attend to participate

Gill planned to conduct a synchronous discussion of the current case ("Taking ISM4300 Online") early in the first week of summer school to give students the opportunity to see a synchronous discussion (either live or, at some later time, recorded) in order to allow them to make a better informed decision. Unlike other synchronous case discussions that might be scheduled later in the semester, this exercise would be highly tolerant of technical and other problems and, under no circumstances, would anyone be penalized for faults in their participation.

\section{Finalizing the Course Syllabus}

In a typical course, decisions relating to grading, deadlines, and online sessions would be finalized before the first session. But the revised ISM4300 was not your typical course! And, prior research suggested that, although students frequently enjoyed the greater flexibility of an online course, they also often believed it required greater self-discipline - a self-discipline that might be aided by a well structured syllabus able to compensate for the lack of in-person interaction [Daymont, T., Blau, G., \& Campbell, D. (2011). Deciding between traditional and online formats: Exploring the role of learning advantages, flexibility, and compensatory adaptation. Journal of Behavioral and Applied Management, 12(2), 156-175]. Thus, Gill felt that the best way to make the decisions described would be to involve the students themselves. Thus, after discussing the case in class, he planned to have the students fill out the online form shown in Exhibit 9. Based upon their responses, he would fill in the to-be-determined (TBD) blanks and post the completed syllabus. 


\section{Exhibit 1: Undergraduate MIS Curriculum at USF}

\section{MIS MAJOR CURRICULUM}

Effective Fall 2007

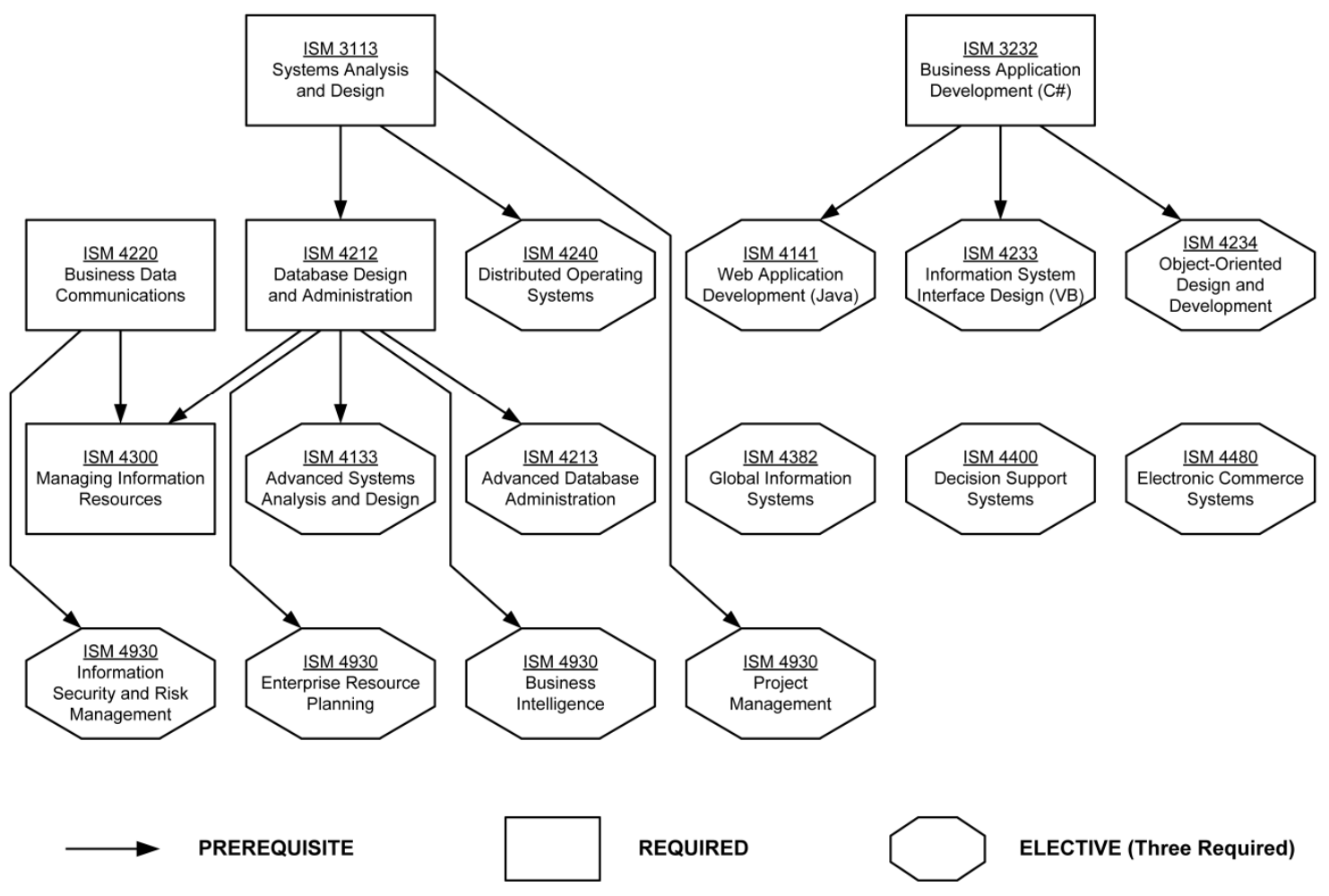




\section{Exhibit 2: Synchronous Discussion using Elluminate}

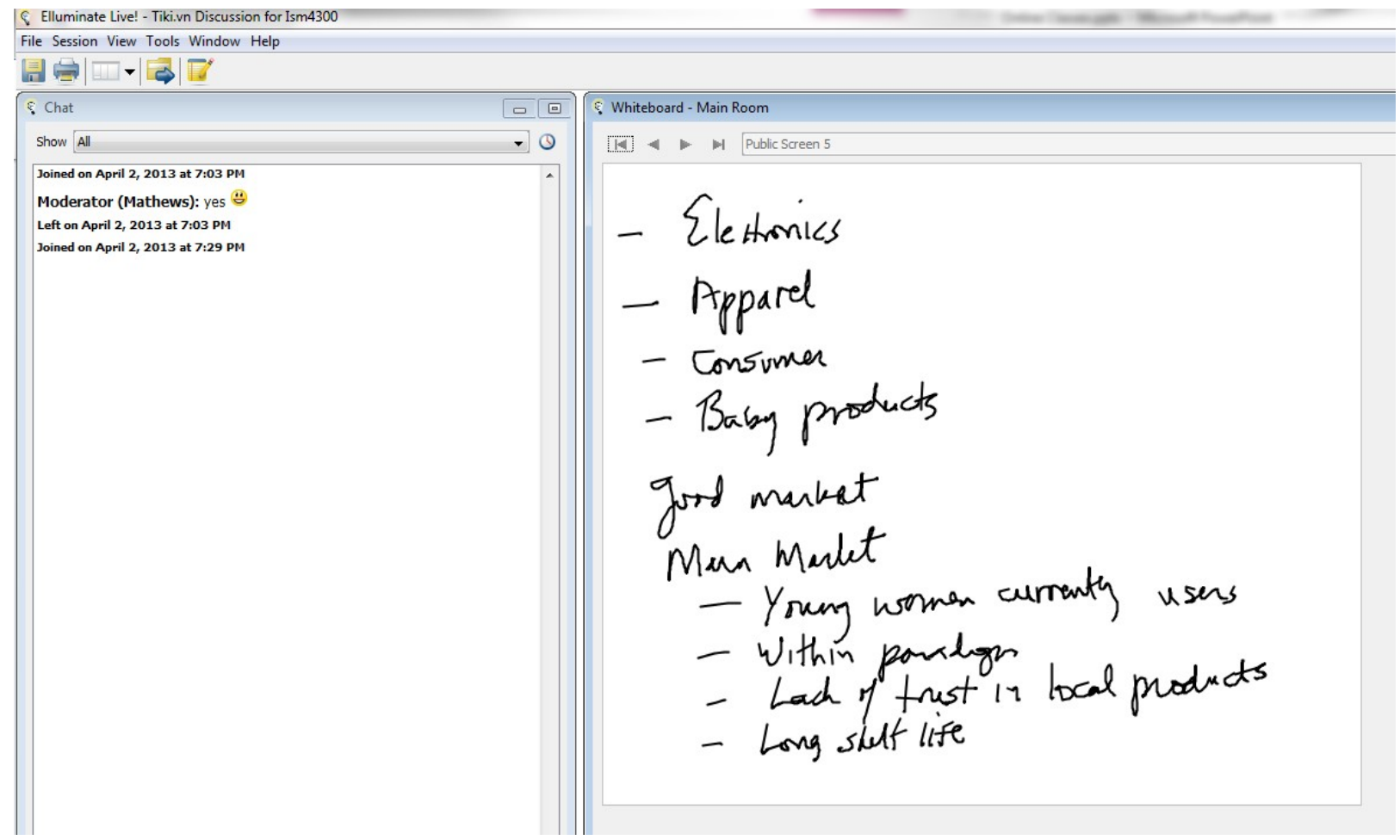

Note: Participant list not shown 


\section{Exhibit 3: Synchronous Discussion using Second Life}

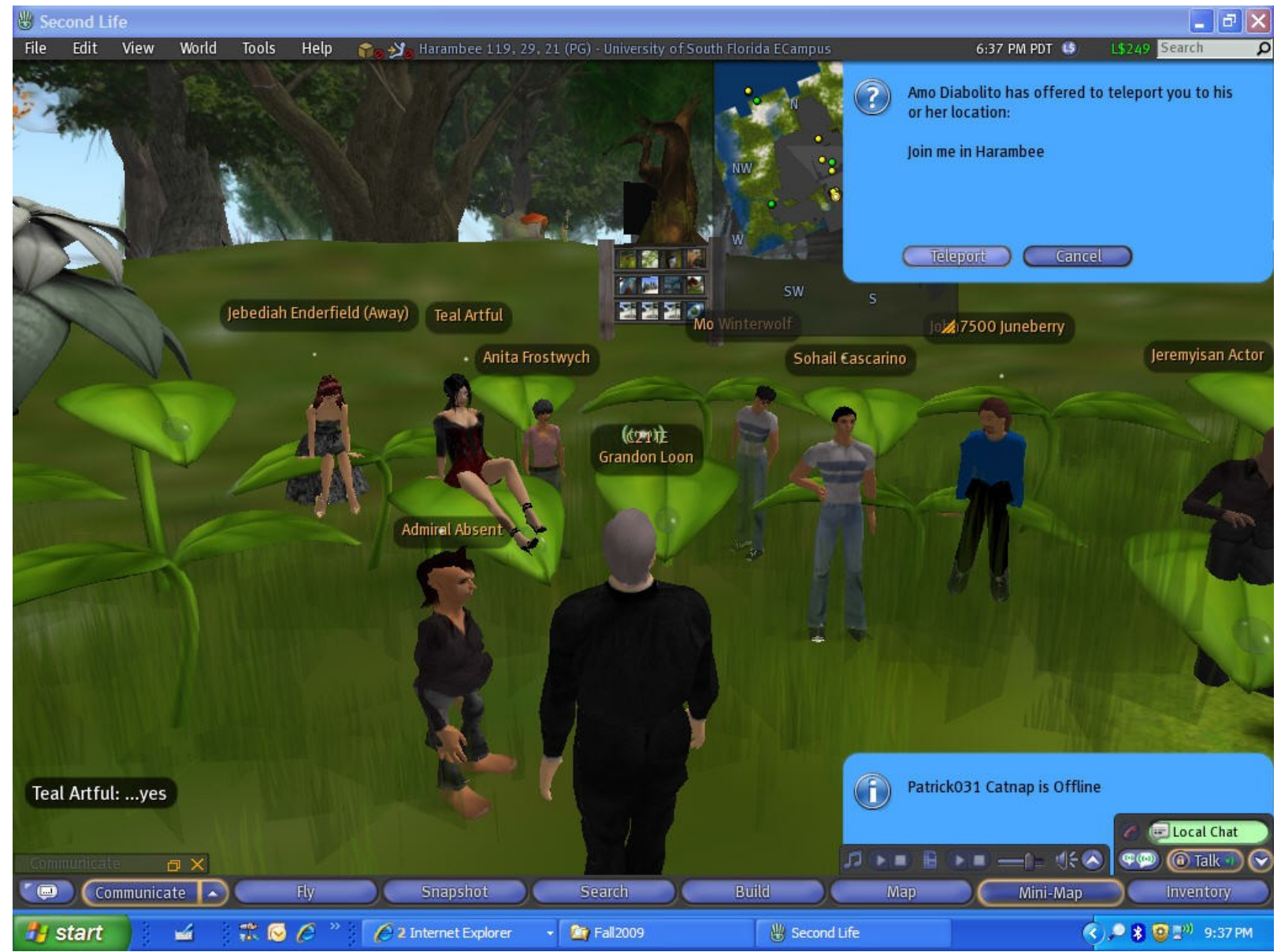




\section{Exhibit 4: Asynchronous Discussion using Canvas}

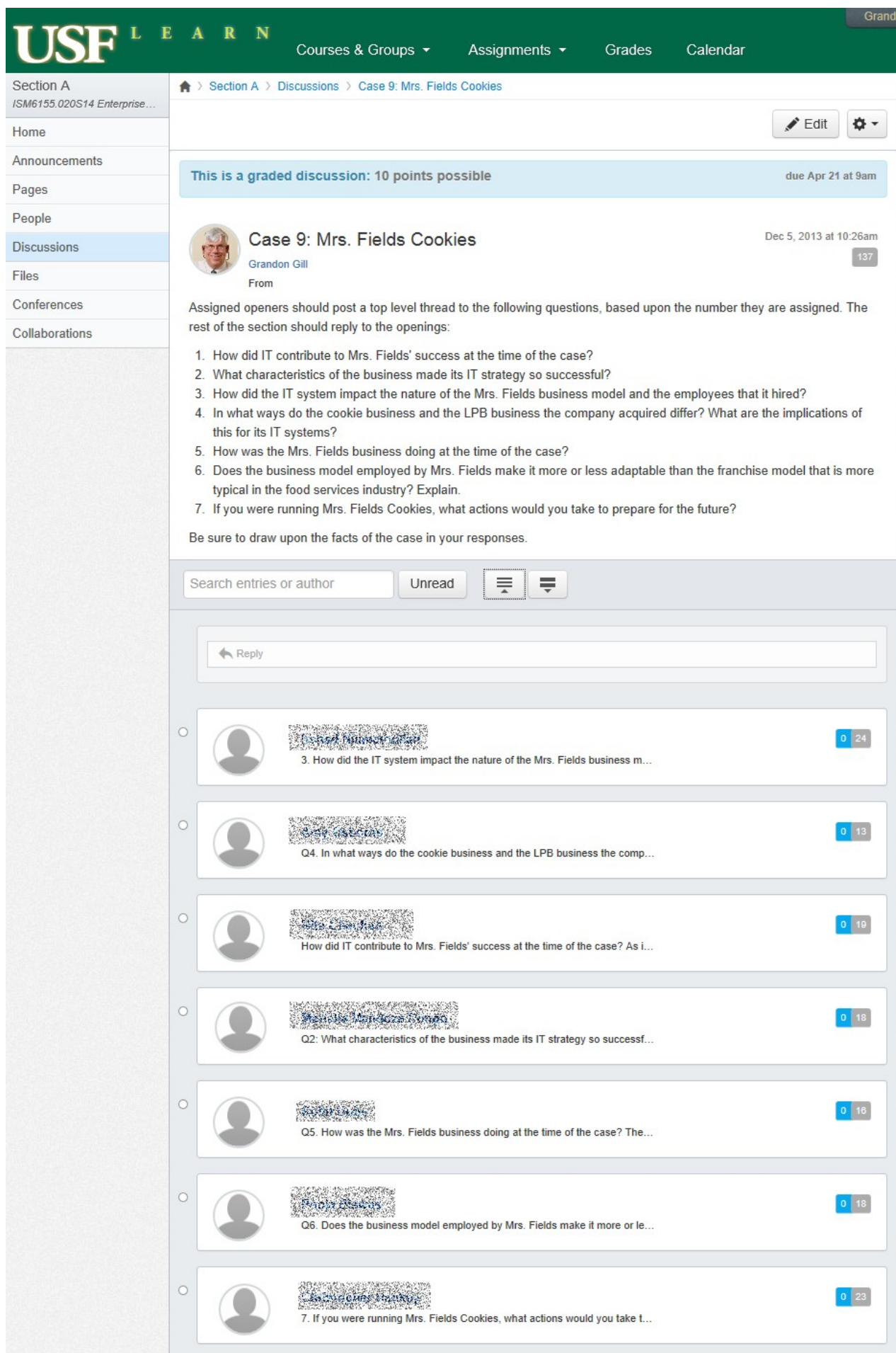

Top level threads, assigned by the instructor to specific students (names hidden disguised for privacy purposes). Numbers in grey boxes on each topic thread show number of posts in that thread. 
0

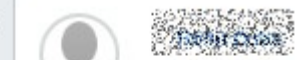

Apr 15, 2014
$\Delta$

Q5. How was the Mrs. Fields business doing at the time of the case?

There are two perspectives to look at Mrs. Fields' business position at the time of the case.

First perspective :

In august they borrowed \$50,000 at opened there first store in Palo Alto, Californis. After one year another store was opened in San Francisco. In 1980 store in Honolulu, Hawaii. In 1981, they opened 14 different stores. 1983 was another major milestone in Fields history when they were able to convince landlords and mall managers for opening store in major locations. After there decision for international expansion in 1982 they had 370 cookie stores in

US, 10 in Canada, 6 in Hong Kong, 7 in Japan, 6 in United Kingdom, and 17 in Australia. In 1984 they acquired Famous Chocolate Chip Company and in April 1987 they acquired PepsiCo a 118 store French bakery/sandwitch chain, La Petite Boulangerie (LPB). LPB's inclusion added \$45 million revenue in 1987.In same year they had \$17.6 million on revenue of $\$ 113.9$ million, $34 \%$ increase from 1986 and $9.3 \%$ increase from 1986 net income.

Again in 1988 they expanded their business to include candies and ice cream. The case also mentions that revenue of each store was around $\$ 250,000$ per year.

Considering the expansion of the business and acquisition of major stores and the healthy revenue generation of each store, we can say that Fields' business was in a very good position during the time of the case.

Second Perspective :

In 1988 the bakery strategy and combination store approach resulted in write off of 19.9 million on $\$ 133.1$ million for store and plant closing left with loss of 18.5 million. The company was in dilemma of growing business. The new strategy demanded major changes in organizational and financial structures. The management information system that has previously proven to be efficient strategy had to be modified to adopt to the new changes.

Statics from Exhibit 1 further clarify their situation. There was increase in the long term debt from 42,734 to 69,732 . Also there was decrease in shareholders' equity and retained earnings from 53,230 to 34,092 as compared to previous year.

To summarize, even if the overall asset value has been increasing, the new business plan had put them in a difficult position. The ability of IS systems to accommodate to the new expanded business will decide the future of Mrs. Fields'

\& Reply

0 Bitions Apr 15, 2014

In regard to the first perspective in mention, the one that related to the expansion of the business. I would like to add that Mrs. Fields Cookies at the time of the case, visibly was a successful and stable company that was maximizinq the advantages of expanding opportunely the business, such as:

- New staff: Adhering new competent people to the company, was a key factor for its expansion, as the personnel , like many other industries, was considered for sure one of its most important assets.

- More customers: With its expansion, the company affronted the challenging task of getting new and diverse customers, fact that dramatically contributed to improve their sales, and thus, resulting in a higher profitability.

- Better financinq opportunities: Mrs. Fields Cookies became a company with an important market share and solid financial position, and therefore the acquisition of additional financial if needed, was not going to represent an inconvenient at all.

\& Reply

0

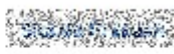

$$
\begin{aligned}
& \text { Apr 16, } 2014
\end{aligned}
$$

No doubt that Mrs. Fields was a well established business generating over $\$ 133$ million revenue by the time of the case. But being precise, at the time of the case, I would only support the second perspective mentioned by Rohit. Although Exhibit 1 presents the income and loss figure for only four years, but the case paints a very clear picture of the continuous growth in its income since its inception. It was for the first time in 1988 that the company incurred such a heavy loss and hence it was a difficult phase for the business. Mrs. Fields' foray into bakery business and the combination store approach does not seem to have settled well with the company thereby upsetting its financial statistics.

Beginning of a discussion thread (names hidden disguised for privacy purposes). 


\section{Exhibit 5: Case Evaluation Form}

Page 1 of 1

Rating this week's case

We are using for to decide what cases to keep or rotate out of the class in future semesters.

1. Your Blackboard NETID (NOT your U number!)*

2. Your last name:*

3. Name of the case*

[Case name listed on board]

4. Please rate the case on the following dimensions*

$\begin{array}{lccccc} & \text { Very Useful } & \text { Useful } & \text { Neutral } & \text { Useless } & \text { Very Useless } \\ \text { Interesting } & \odot & \odot & \odot & \odot & \bigcirc \\ \text { Relevant } & \odot & \odot & \odot & \odot & \bigcirc \\ \text { Useful } & \odot & \odot & \odot & \odot & \bigcirc \\ \text { Unexpected } & \odot & \odot & \odot & \bigcirc & \odot \\ \text { OVERALL } & \odot & \odot & \odot & \odot\end{array}$

\section{Done Save Cancel}




\section{Exhibit 6: Project Description from Course Syllabus}

\section{Project Elements}

\section{Project types}

The purpose of the project is to demonstrate some technological or research skill that you have acquired over the course of the MIS major. The project is individual (no group) should involve substantial complexity and will generally center around one of the following areas:

- A programming project: A stand-alone or web-based project that involves substantial coding in a programming language such as C\#, VB or Java. Mobile apps or web-based projects involving PHP or some other environment (ASP, Ruby-on-Rails) will also be allowed.

- A database project: A project built around designing an SQL-based database (as well as related forms, queries and reports) for a particular business situation. Real-world or test data may be used.

- An analysis and design project: A project built around designing a system or application. Appropriate diagrams (ER, UML) should be prepared, along with form layouts, business process diagrams and project plans.

- A real-world web site: For pure web site projects, a real-world client is required. Such a client may be identified by the student or, from time to time, may be supplied by the instructor. A thorough needs analysis and approach to determining the effectiveness of such a site will be required for this category of project.

- A real-world case study: Students working in business or facing complex career decisions may choose to develop a case study that is intended for use in subsequent offerings of ISM4300. These projects will need to be developed in close collaboration with the instructor and will necessarily demand a very high standard of quality.

- A research white paper: An in-depth research paper-20 pages in length or more - that explores a particular technology, such as WiMax, or MIS issue, such as outsourcing. Safe Assignment will be used to ensure that the work is original. You should have a substantial number of sources and should cite them.

\section{Project meetings}

Throughout the semester, we will be available to schedule online synchronous sessions with students to discuss their projects.

\section{Project proposals}

Early in the semester, students will submit project proposals. Forms for different projects types will be provided on Canvas. We will provide comments on these proposals, and approve them when they are in a form that makes sense. Students should not begin serious work on their projects until they have approval.

\section{Posters}

Each student will prepare a poster describing his or her project. These posters will be uploaded as a PDF file (Note: recent versions of PowerPoint can save to PDF) to an assignment labeled "Project Posters". Students will be assigned to peer review specified posters and presentations created by their classmates. Posters should either be roughly 36x48" (portrait) or 48x36" (landscape). Some sample PowerPoint templates are provided in the "Permanent Resources" module on Canvas. [TBD: Students may use other templates or even other programs (such as Prezi or a publishing program) provided they match the size dimensions.] At or near the top of each poster should be included: 
- Student Name

- Project Title

- $\quad$ Project ID

\section{Poster presentations}

Each student will prepare a video presentation describing his or her project, lasting no longer than 10 minutes. [TBD: The format can be PowerPoint (with voice-over), mp4, YouTube or Prezi with an audio track. The presentations, or link to the streaming site, will be attached to a discussion posting named "Project Presentations". If your project involves programming or technology that needs to be demonstrated on a PC, you can use programs such as Camtasia ( $\$ 20$ for 3 year license at bookstore; 30 day trial is free), Jing (free, but limited to 5 minutes) or the open source CamStudio (free) to make screen recordings if you need to. These can be attached — in mp4 format — or uploaded to Youtube.] The text portion of each posting will include:

- Student Name

- Project Title

- Project ID

As part of their peer review of classmate projects, students must watch the presentation associated with an assigned poster. A web form that evaluates posters, presentations and the overall project must be filled out as part of the peer review.

\section{Final project Write-ups}

Students will submit a final project report, which is a written version of their project. A typical project report will contain:

1. A short summary explaining why you chose the particular project

2. A written document that describes the project in detail. Within the report you should include:

a. Pasted source code and screen shots for technical projects

b. Diagrams from database and analysis \& design projects

c. A list of properly cited references for research and case study projects

3. A page or two explaining what you learned from the project

Project reports are due on the last regular day of classes, as specified on Canvas. The report should be in the form of a single Word document. The size and scope of these reports will vary according to the nature of the project. For a programming project, aside from the introductory summary and "lessons learned", the report might consist mainly of code snippets and screen shots; other projects involving technology development will likely be similar. For a white paper project or case study, on the other hand, the report will represent the most import part of the project. These will be uploaded to the designated assignment area in Canvas.

\section{Presentation peer evaluations}

Those students not presenting will evaluate each student's poster during the poster session using online forms that I will provide (see illustration below). These forms will be evaluated, and will be used in evaluating the projects. 


\begin{tabular}{|c|c|c|c|c|c|}
\hline & 1 & 2 & 3 & 4 & 5 \\
\hline $\begin{array}{l}\text { Project } \\
\text { Difficulty }\end{array}$ & 0 & 0 & $\odot$ & $\odot$ & $\odot$ \\
\hline $\begin{array}{l}\text { Project } \\
\text { Quality }\end{array}$ & 0 & 0 & 0 & ○ & 0 \\
\hline $\begin{array}{l}\text { Presentation } \\
\text { Quality }\end{array}$ & 0 & $\odot$ & 0 & 0 & 0 \\
\hline
\end{tabular}

\section{Project grading}

Projects will be graded based upon the difficulty of the project and the quality of its components. Presentation peer evaluations will be included in this assessment. 


\section{Exhibit 7: Guidelines for Discussion Participation from Course Syllabus}

\section{Before each case: Preparation}

Students should expect to spend 2-3 hours preparing each case study. Preparing a case typically involves:

- $\quad$ Reading the case

- Making notes and analyzing the case during a careful second reading

The discussion will open precisely one week before the "Due Date" in the syllabus, which will be on a Monday, at 9am.

Tuesday of the week when a case is discussed: Opening questions

For each case, 6-7 questions will be posted, along with the name of each student assigned to respond to the question (each student will open 2-3 times during the semester). By Tuesday at 9 pm of the week that a case is being discussed, each student assigned to open should post his or her response.

Case discussion week: Participating in the discussion

Once an opening response has been posted, the rest of the section should enter the discussion. Each student should feel free to respond with as many posts desired. Each student's participation in every discussion will be graded (although the first discussion will be viewed as a source of "extra credit" only, as everyone will be learning the ropes).

What we typically look for in discussions is the following:

- Is the poster responding to another student's comments? If so, it helps if you give the name of the student, since the number of posts can become quite large.

- Agreeing with a previous post without adding something new gets you nothing. If, on the other hand, you agree and then point out something that was missed or requires clarification, that is fine.

- Disagreeing with a previous post — provided a good explanation of why you disagree in included - is considered in a very positive light.

- Repeating what someone else said simply bloats the discussion; you should always strive to add something new. The earlier an idea is posted, the more likely it will be credited.

- High quality posts will frequently include specific references to facts in the case that you believe are important. You may also reference outside sources if you found them to be valuable.

- If all your posts appear to have been made in one setting (their dates and times cluster together), we will normally deduct points. We like to see back and forth in a discussion and that cannot happen when students enter the discussion for just one session.

Each week, discussions will be graded on a scale of:

- $5=$ Excellent

- $4=$ Better than average

- $3=$ Satisfactory

- $2=$ Below average

- $1=$ Weak

- $0=$ Unsatisfactory or missing 


\section{Exhibit 8: Discussion and Reflection Rubrics}

\section{Course Rubrics}

\begin{tabular}{|c|c|c|c|}
\hline \multicolumn{3}{|l|}{ Discussion Participation } & \multirow{2}{*}{$\frac{\text { 而 }}{\text { Pts }}$} \\
\hline Criteria & & atings & \\
\hline $\begin{array}{l}\text { Integrates with Discussion } \\
\text { view longer description }\end{array}$ & $\begin{array}{l}\text { Good integration } \\
1 \text { pts }\end{array}$ & $\begin{array}{l}\text { Posts stand alone } \\
0 \text { pts }\end{array}$ & 1 pts \\
\hline $\begin{array}{l}\text { Consistent participation } \\
\text { view longer description }\end{array}$ & $\begin{array}{l}\text { Reasonable spread of postings } \\
1 \text { pts }\end{array}$ & $\begin{array}{l}\text { Posts in narrow time window } \\
0 \text { pts }\end{array}$ & $1 \mathrm{pts}$ \\
\hline $\begin{array}{l}\text { Use of case facts } \\
\text { view longer description }\end{array}$ & $\begin{array}{l}\text { Good use of case facts } \\
1 \text { pts }\end{array}$ & $\begin{array}{l}\text { Posts are mainly opinion } \\
0 \text { pts }\end{array}$ & $1 \mathrm{pts}$ \\
\hline $\begin{array}{l}\text { Quality of language } \\
\text { view longer description }\end{array}$ & $\begin{array}{l}\text { Effective use of language } \\
1 \text { pts }\end{array}$ & $\begin{array}{l}\text { Sloppy use of language } \\
0 \text { pts }\end{array}$ & $1 \mathrm{pts}$ \\
\hline $\begin{array}{l}\text { Novelty of ideas } \\
\text { view longer description }\end{array}$ & $\begin{array}{l}\text { Post offers new insights } \\
1 \text { pts }\end{array}$ & $\begin{array}{l}\text { Post mainly repeats past posts } \\
0 \text { pts }\end{array}$ & 1 pts \\
\hline
\end{tabular}

\begin{tabular}{|c|c|c|c|}
\hline \multicolumn{3}{|l|}{ Post-Case Reflections } & \multirow{2}{*}{ Pts } \\
\hline Criteria & \multicolumn{2}{|c|}{ Ratings } & \\
\hline $\begin{array}{l}\text { Follows specified format } \\
\text { view longer description }\end{array}$ & $\begin{array}{l}\text { Yes } \\
1 \text { pts }\end{array}$ & $\begin{array}{l}\text { No } \\
0 \text { pts }\end{array}$ & $1 \mathrm{pts}$ \\
\hline $\begin{array}{l}\text { Lessons relate to case study } \\
\text { view longer description }\end{array}$ & $\begin{array}{l}\text { Relate to case } \\
1 \text { pts }\end{array}$ & $\begin{array}{l}\text { General or self-evident } \\
0 \text { pts }\end{array}$ & $1 \mathrm{pts}$ \\
\hline $\begin{array}{l}\text { Learning relates to discussion } \\
\text { view longer description }\end{array}$ & $\begin{array}{l}\text { Relate to discussion } \\
1 \text { pts }\end{array}$ & $\begin{array}{l}\text { Relationship not evident } \\
1 \mathrm{pts}\end{array}$ & $1 \mathrm{pts}$ \\
\hline $\begin{array}{l}\text { Centrality of identified issues } \\
\text { view longer description }\end{array}$ & $\begin{array}{l}\text { Mainly important issues } \\
1 \text { pts }\end{array}$ & $\begin{array}{l}\text { Mainly minor issues } \\
0 \text { pts }\end{array}$ & $1 \mathrm{pts}$ \\
\hline $\begin{array}{l}\text { Quality of writing } \\
\text { view longer description }\end{array}$ & $\begin{array}{l}\text { Well written } \\
1 \text { pts }\end{array}$ & $\begin{array}{l}\text { No Marks } \\
\text { O pts }\end{array}$ & $1 \mathrm{pts}$ \\
\hline \multicolumn{4}{|c|}{ Total Points: 5} \\
\hline
\end{tabular}


1. Choose your preferred balance between participation and project*
$70 \%$ Participation and $30 \%$ Project
$60 \%$ Participation and $40 \%$ Project
$50 \%$ Participation and $50 \%$ Project
$40 \%$ Participation and $60 \%$ Project
$30 \%$ Participation and $70 \%$ Project

2. How do you want discussion participation to be assessed?*

Using a strict rubric with points for each item

Using a flexible scheme

3. For your participation grade, which weighting would you prefer?*

Heavy on the classroom discussion

Balance of discussion and written work

Heavy on the written forms

4. How should deadlines be enforced?*

Strictly, with no late submissions accepted

Late submissions accepted with penalty

Late submissions accepted without penalty

5. How strictly should project deliverable formats be specified?*

Maximum flexibility to student

Flexible presentation format; specify poster styling

Specify presentation format; flexible poster styling

Specify both presentation format and poster styling

6. Should synchronous case discussion sessions be conducted?*

Not after the first week

Yes, but only if guests plan to attend

Yes, at times that vary from week to week

\section{Done

